How to cite

Kaushal, R. K., \& Panda, S. N. (2019). A meta analysis on effective conditions to offer animation based teaching style. Malaysian Journal of Learning and Instruction, 16(1), 129-153.

\title{
A META ANALYSIS ON EFFECTIVE CONDITIONS TO OFFER ANIMATION BASED TEACHING STYLE
}

\author{
${ }^{1}$ Rajesh Kumar Kaushal \& Surya Narayan Panda \\ Chitkara University Institute of Engineering \& Technology, \\ Chitkara University, Punjab, India

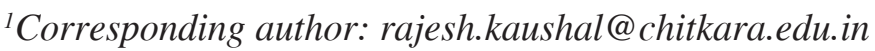

Received: 29 June 2018 Revised: 19 February 2019 Accepted: 26 March 2019

\begin{abstract}
Purpose - The aim of this study is to find in which conditions animation based teaching style for example teaching through 2D or 3D animations or animated diagrams leads to the better learning outcome. To achieve this purpose, we compared these two conditions (i) animation based teaching style is effective when offered to high spatial ability learners versus low spatial ability learners (ii) animation based teaching style is effective when offered to high prior knowledge learners versus low prior knowledge learners.
\end{abstract}

Methodology - The data of 37 experiments from 22 different published studies were collected to identify the effective conditions. The results were obtained by conducting a meta-analysis. Animations can be effective for a wide range of subject disciplines and age group. Therefore, the present study incorporated published empirical data from different subject disciplines and age groups.

Findings - The weighted mean effect size of HSA and LSA groups were 0.34 and 0.58 respectively. Thus, the current study is able to reject the null hypothesis that animation based teaching style is only effective for HSA students. The weighted mean effect size of HPK 
and LPK groups were 0.49 and -0.16 respectively. As a result, this study is unable to reject the null hypothesis that animation based teaching style is only effective for HPK students.

Significance - This study statistically proved that prior knowledge is a crucial factor while offering animation based teaching style and thus it should only be offered to HPK students. Whereas, spatial ability is not a crucial factor as both high and low spatial ability students performed positively with animation based teaching style. These facts can help educators to design teaching methodologies to enhance the learning outcomes.

Keywords: Animation based teaching style, spatial ability, prior knowledge, individual differences.

\section{INTRODUCTION}

\section{Animation Based Teaching Style and its Impact}

For a long time, researchers have been trying to establish better learning outcomes that can be achieved through different cognitive styles (Azman, Mohd Ali, Tamuri, \& Mohd Jelas, 2005). Most of these researchers focused on teaching students through static and dynamic learning style. Static teaching style includes learning through traditional methods like printed materials whereas dynamic cognitive teaching style includes teaching through 2D and 3D animations or animated diagrams etc. The animation based teaching style is effective for topics which require changes over time and space (Ainsworth \& VanLabeke, 2004; Rieber, 1990) .

The past empirical studies in this area do not present uniform results. Few studies found the animated environment as an effective teaching methodology (Berney \& Bétrancourt, 2016; Höffler \& Leutner, 2007; Large, Beheshti, Breuleux, \& Renaud, 1996; Mayer \& Anderson, 1992; O. Park \& Gittelman, 1992; Rieber, 1990; Stebner, Kühl, Höffler, Wirth, \& Ayres, 2017) while there are a few other studies that found it ineffective (Boucheix \& Schneider, 2009; Byrne, Catrambone, \& Stasko, 1999; Hegarty, Kriz, \& Cate, 2003; Mayer, DeLeeuw, \& Ayres, 2007; Narayanan \& Hegarty, 2002; Tversky, Morrison, \& Betrancourt, 2002). These non-uniform outcomes encourage researchers to further investigate the reasons 
that enhances dynamic cognitive style as more effective and in some cases the reasons for not being successful. This resulted in researchers investigating effective conditions to offer animations (Hegarty, 2004; Höffler, Prechtl, \& Nerdel, 2010; Tversky et al., 2002). Initially, they concluded that animations sometimes may not be effective due to its transitory nature (Chandler, 2004; Lowe, 1999).

The transitory nature implies that in an animated environment frame, appears and disappears continuously and this results in learners not having sufficient time to grasp the concept. This transitory nature increases cognitive load and consequently influences the learning outcome (Moreno \& Mayer, 2007; Paas, Renkl, \& Sweller, 2003). Subsequently, it was observed that the same learning environment has a different impact on learners as it may be due to individual differences. Indeed, individuals may have their own learning style (Abdullah \& Ligon, 2006).

The two prominent individual differences are the learner's spatial ability and prior knowledge. This is due to the fact that all students are not the same and do not possess the same learning ability, so the emphasis should be on finding the impact of individual differences and cognitive style on learning-outcome. This research paper explores when the animation based teaching style is effective (a) when it is offered to high spatial ability students or low spatial ability students and (b) when it is offered to high prior knowledge students or low prior knowledge students.

Animations have been commonly used in education across a wide range of subject disciplines (Nguyen, Nelson, \& Wilson, 2012). The present study is not bound to a specific subject discipline. Moreover, it incorporates data from various subject disciplines of secondary school, high school, and university students.

\section{Animations and Prior Knowledge}

The literature related to individual differences, cognitive style, and learning outcome depicts that individual differences effects learning outcome, regardless of any cognitive style. Prior knowledge is one of the key individual differences that can affect the learning outcome (Canham \& Hegarty, 2010; ChanLin, 2001; Hegarty, Canham, \& Fabrikant, 2010; Johnson, Ozogul, \& Reisslein, 2015; Kalyuga, 
2008; Kriz \& Hegarty, 2007; Malakolunthu \& Joshua, 2012). It is associated with the learner's prior knowledge of the domain area. As a result, learners are generally classified into high and low prior knowledge groups for empirical studies. These groups are also named as expert group and novices group.

For a long time, researchers have been attempting to recognize which cognitive style is productive for the low prior knowledge learners and which is effective for the high prior knowledge learners. The previous researches in this area have demonstrated diverse outcomes. In some studies, experts have proven that there is evidence of improved learning outcome when taught through animations or dynamic learning material. (Kalyuga, 2008; Khacharem, Zoudji, Kalyuga, \& Ripoll, 2013; S. I. Park, Lee, \& Kim, 2009) However in other studies (Malone \& Brünken, 2013; Ollerenshaw, Aidman, \& Kidd, 1997), it indicated otherwise. The similar pattern is observed for novices.

It is also said that the treatment designed for LPK learners may not be as effective for HPK learners (Kalyuga, 2008). Moreover, the effectiveness of animations for experts may decrease due to redundant information (Kalyuga, Chandler, \& Sweller, 1998; Kalyuga \& Sweller, 2005). This effect is known as the expertise reversal effect and is proved by past experimental studies (Kalyuga, Chandler, \& Sweller, 2000, 2001; Kalyuga, 2007). In fact, the redundancy is beneficial for novices (Mayer \& Gallini, 1990). Redundancy occurs when multiple sources of information are presented in the same cognitive style (Kalyuga et al., 2000).

Therefore, it is evident that the results of the empirical studies published in the past are not uniform and further investigation is required to find when animations are more effective when they are offered to novices or experts. Thus, effective conditions may be exposed to the education community by investigating published studies using statistical techniques. This is one of the research goals of this study.

\section{Animations and Spatial Ability}

The spatial ability is also one of the key individual differences that can influence the learning outcome (Berney, Bétrancourt, Molinari, 
\& Hoyek, 2015). The spatial ability is associated with the ability to generate, maintain and manipulate objects. These objects may be animated models of concepts (Brünken, Steinbacher, \& Leutner, 2000; Mayer \& Sims, 1994). When learners are exposed to animate concepts mentally for comprehension, then learning outcomes is subjected to spatial ability (Cornoldi \& Vecchi, 2004; Hegarty \& Kozhevnikov, 1999; Hegarty \& Waller, 2005; Sims \& Hegarty, 1997).

It is believed that HSA learners can easily rotate and manipulate $2 \mathrm{D}$ or $3 \mathrm{D}$ objects in their mind due to high cognitive resources in developing a mental model of a concept during learning from visual representations (Huk, 2006; Mayer \& Sims, 1994). The LSA learners do not have such abilities. The learners are categorized into HSA or LSA groups primarily through the mental rotation test (Peters et al., 1995; Vandenberg \& Kuse, 1978) or paper folding and card rotation test (Ekstrom, Dermen, \& Harman, 1976).

There is a general assumption that low spatial ability students may face difficulties while learning through animations. Some researchers are of the opinion that animations may help LSA students (Hegarty \& Kriz, 2008; Hegarty, 2005; E. A.-L. Lee \& Wong, 2014) as they are unable to make mental models of the concept and offering animations to such students are like offering a ready-made model.

The past literature associated with this issue does not show uniform outcomes. In fact, some studies could not prove any interaction between spatial ability and animation based teaching style (Hegarty et al., 2003; Hegarty, 2004; Narayanan \& Hegarty, 2002). On the other hand, some studies have proved the effectiveness of animations when taught to HSA students (A. Garg, Norman, Spero, \& Maheshwari, 1999; A. X. Garg, Norman, \& Sperotable, 2001; Isaak \& Just, 1995; Mayer \& Sims, 1994).

Further research is essential to investigate the overall effect of spatial ability and animation based teaching style on learning-outcome. In this research paper, one of the objectives is to find which condition is more productive, offering animations to LSA students or HSA students. 


\section{OBJECTIVES}

The aim of the current study is to find answers to two research questions. The first research question is to find which condition is more effective, animations for HSA learners or animations for LSA learners. The null and alternate hypothesis is stated as $\mathrm{H}_{0}$ and $\mathrm{H}_{1}$.

$\mathrm{H}_{0} \quad$ : Animation based teaching is only effective for HSA students.

$\mathrm{H}_{1} \quad$ : Animation based teaching is effective for both HSA and LSA students.

The second research question is to find which condition is more effective, animations for HPK learners or animations for LPK learners. The null and alternate hypothesis is stated as $\mathrm{H}_{0}$ and $\mathrm{H}_{1}$.

$\mathrm{H}_{0} \quad$ : Animation based teaching is only effective for HPK students.

$\mathrm{H}_{1} \quad$ : Animation based teaching is effective for both HPK and LPK students

\section{METHODOLOGY}

The published empirical data (1994 - 2016) is used to find the answers to the research questions. The combination of descriptors such as 'animations and spatial ability', 'animations and prior knowledge', 'experts, novices and animations', 'individual differences and animations', 'individual differences and dynamic visualizations' etc. were used to locate the studies. After exclusion, data of 37 experiments were gathered ( 20 related to spatial ability, animations, and learning outcomes and 17 related to prior knowledge, animations, and learning outcomes) from 22 distinct studies where 15 studies are indexed in SSCI database and 3 studies are indexed in SCOPUS database.

Only those spatial ability (See Table 1) and prior knowledge (See Table 2) studies were included in which, groups were taught through animated (2D or 3D animations, animated diagrams or dynamic 
Malaysian Journal of Learning and Instruction: Vol. 16 (No. 1) June 2019: 129-153 135

visualizations) and non-animated (static images or traditional classrooms) environment and the learning outcomes were measured. Animations can be effective for a wide range of subject disciplines; the difference in the learning outcome is due to the individual differences (learner's spatial ability and prior knowledge). Therefore, the present study incorporates published empirical data of a wide range of subject discipline. The articles were searched on Science Direct, Citeseer, and Google Scholar.

At first, the Cohen's d effect sizes of all the experiments were calculated. The Cohen's d equation is a little bit biased (Hedges \& Olkin, 1985) especially when the sample size is less than 20 . To avoid the bias, the Hedges g equation on Cohen's d values were applied. Thereafter, the weighted mean effect sizes of all the experiments associated with LSA, HSA, LPK, and HPK were calculated to find the magnitude and direction. Then the LSA and HSA mean effect sizes were compared. The same methodology was used with LPK and HPK learners.

The Hedges $g$ value was not computed for those experiments where the value of $\mathrm{N}$ (population size) was missing and Cohen's d value was used as it is. There were 6 such experiments out of 37 where the value of $\mathrm{N}$ was missing. The equation below was utilized to compute the Cohen's d effect size.

(1) $\quad d=\frac{\overline{X_{t}}-\overline{X_{c}}}{S_{\text {pooled }}}$

As per the first equation, effect size $\mathrm{d}$ can be calculated by subtracting the mean of the control group from the mean of the treatment group and then divided by pooled standard deviation. The pooled standard deviation is then calculated by using the following equation:

(2) $S_{\text {pooled }}=\sqrt{\frac{\left(n_{1}-1\right) s_{1}^{2}+\left(n_{2}-1\right) s_{2}^{2}}{n_{1}+n_{2}-2}}$ 
In the second equation, $\mathrm{n}_{1}$ and $\mathrm{n}_{2}$ are sample sizes of treatment and control group respectively and $\mathrm{s}_{1}$ and $\mathrm{s}_{2}$ are standard deviations of the treatment and control group respectively. In case the value of $\mathrm{N}$ is not given, then the underneath equation can also be used to compute the effect size which results in a fair estimate.

(3) $S_{\text {pooled }}=\sqrt{\left(\left(S D_{1}^{2}\right)+S D_{2}^{2} / 2\right)}$

In the third equation, $\mathrm{SD}_{1}$ and $\mathrm{SD}_{2}$ are the standard deviations of the treatment group and the control group respectively. Then the weighted mean effect size is calculated using the fourth equation.

(4) $\quad M E S=\frac{\sum_{n=1}^{T S} E S_{n}}{T S}$

The TS in the fourth equation stands for the total number of experiments and ES stands for effect size of individual experiments. The bias in Cohen's $d$ value is removed using hedges recommendation (Hedges and Olkin, 1985) stated below in the fifth equation.

(5) Hedge's $g=$ Cohen's $d \times\left(1-\frac{3}{4\left(n_{1}+n_{2}\right)-9}\right)$

\section{DATA COLLECTION}

\section{Spatial Ability, Teaching Style and Learning Outcome}

Table 1 demonstrates the effect sizes of an animated environment, non-animated environment and spatial ability on the learning outcome of HSA and LSA groups. To achieve the purpose, relevant published empirical data of various subject disciplines were gathered.

The data set includes empirical data from different areas like mechanical, medical, chemistry, biology and language learning. Most of the research was on the impact of spatial ability and animation based teaching style on the learning outcome, which was conducted in these areas. 


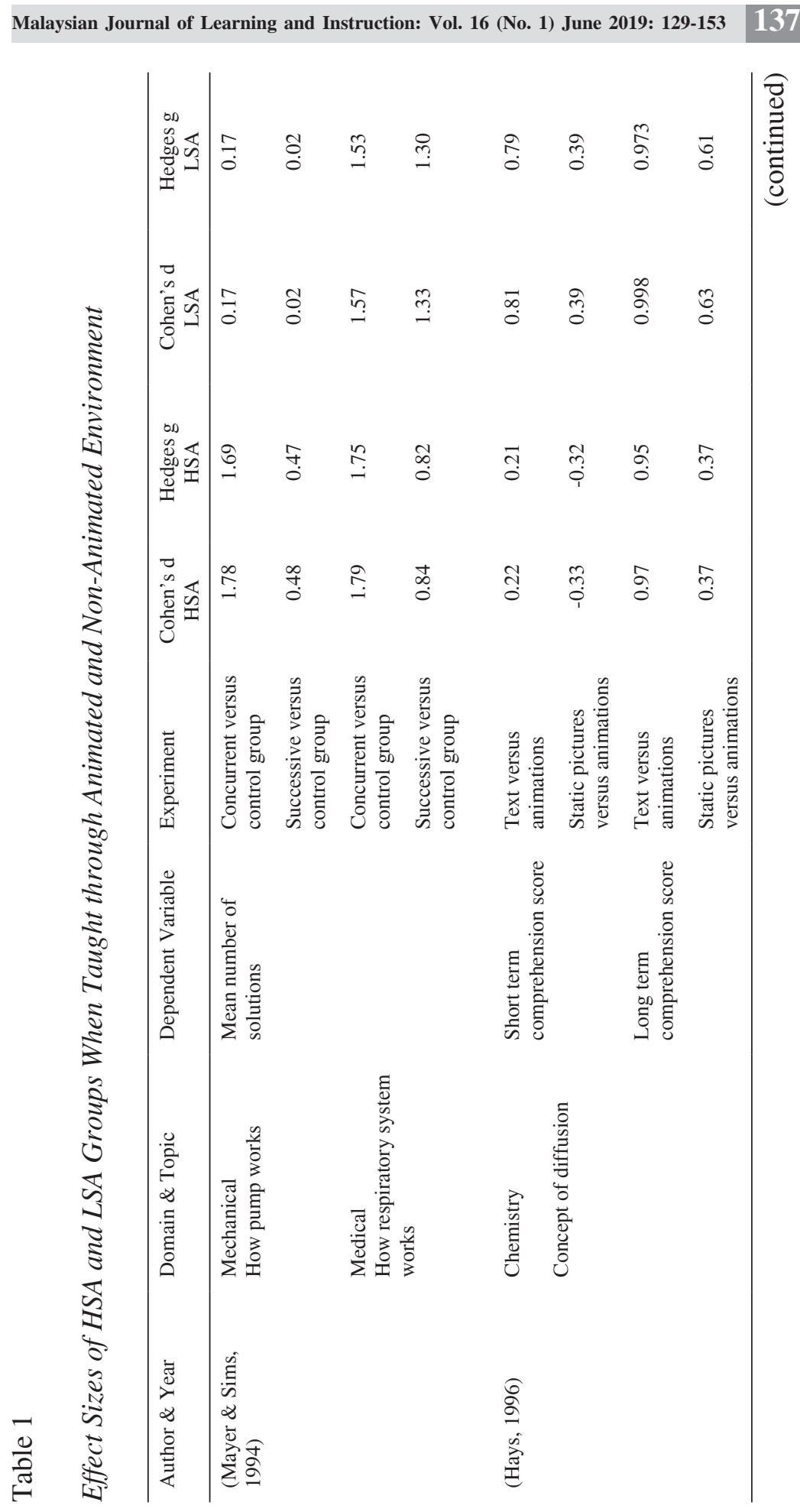


138 Malaysian Journal of Learning and Instruction: Vol. 16 (No. 1) June 2019: 129-153

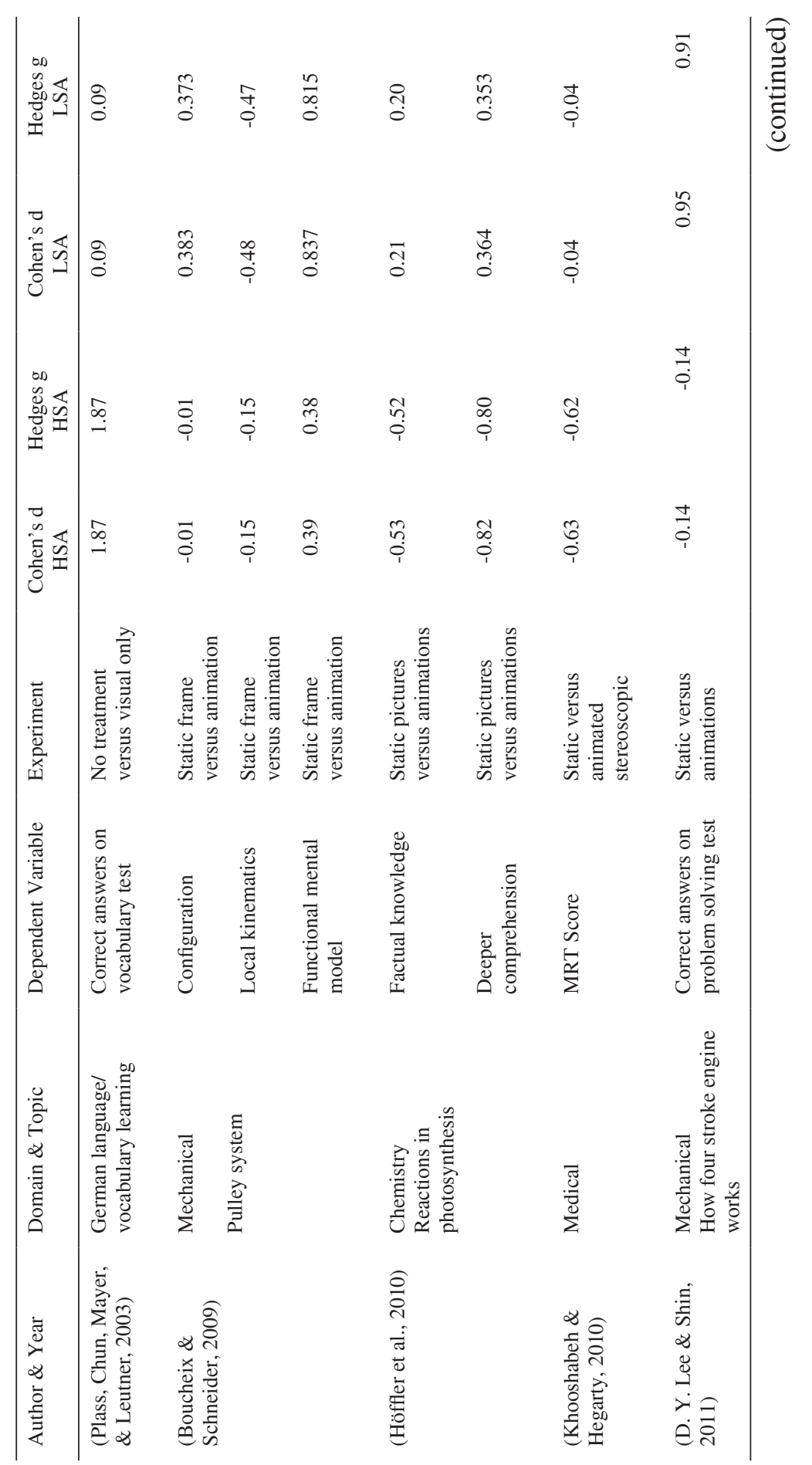


Malaysian Journal of Learning and Instruction: Vol. 16 (No. 1) June 2019: 129-153 139

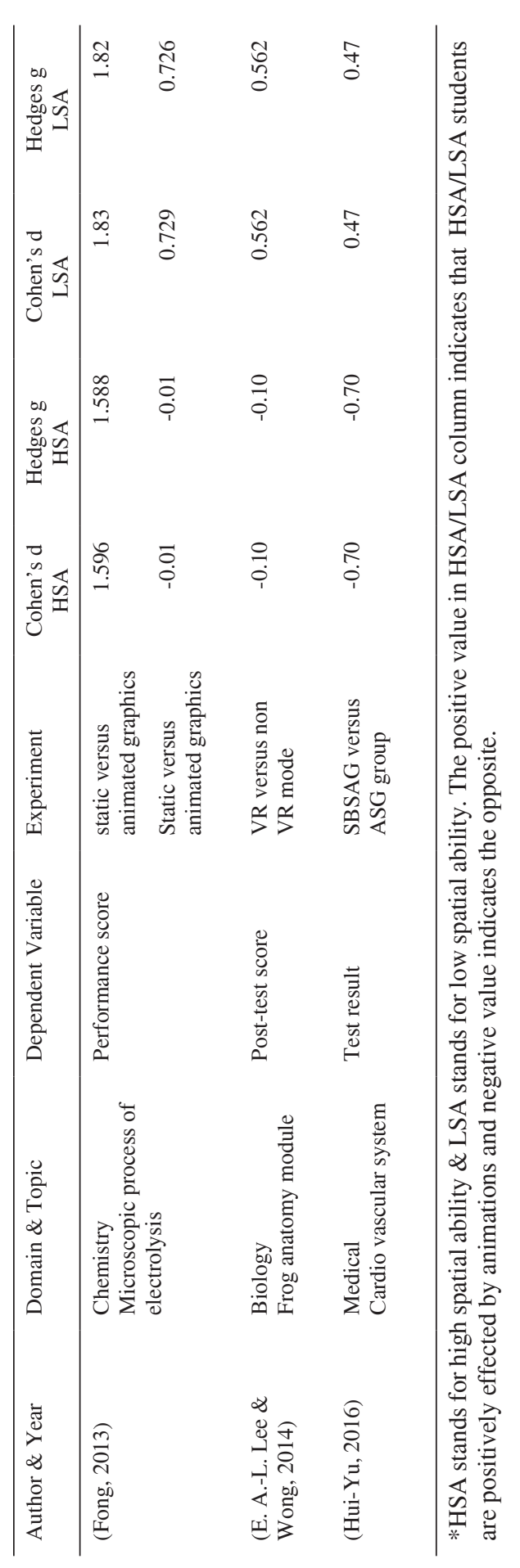




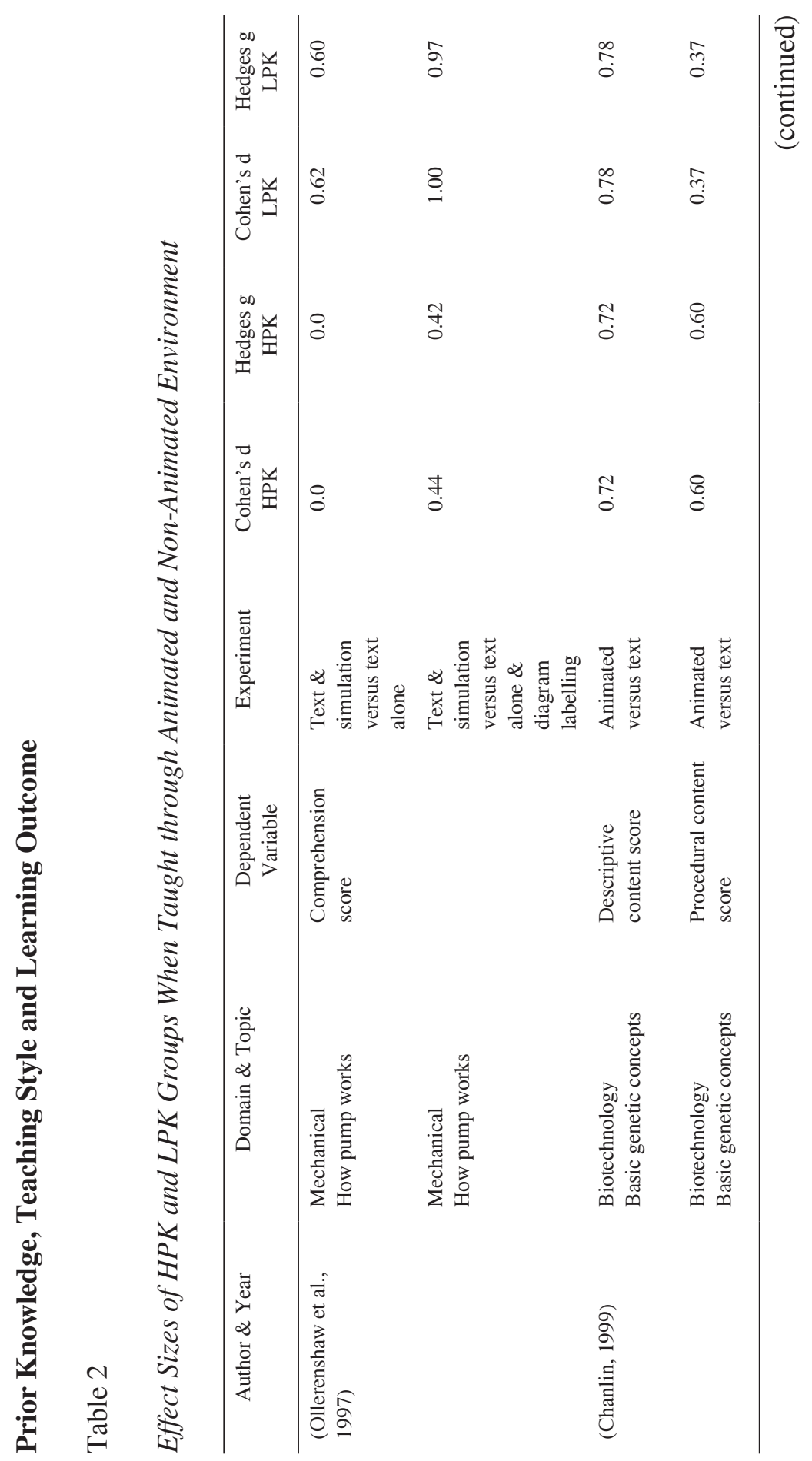


Malaysian Journal of Learning and Instruction: Vol. 16 (No. 1) June 2019: 129-153 141

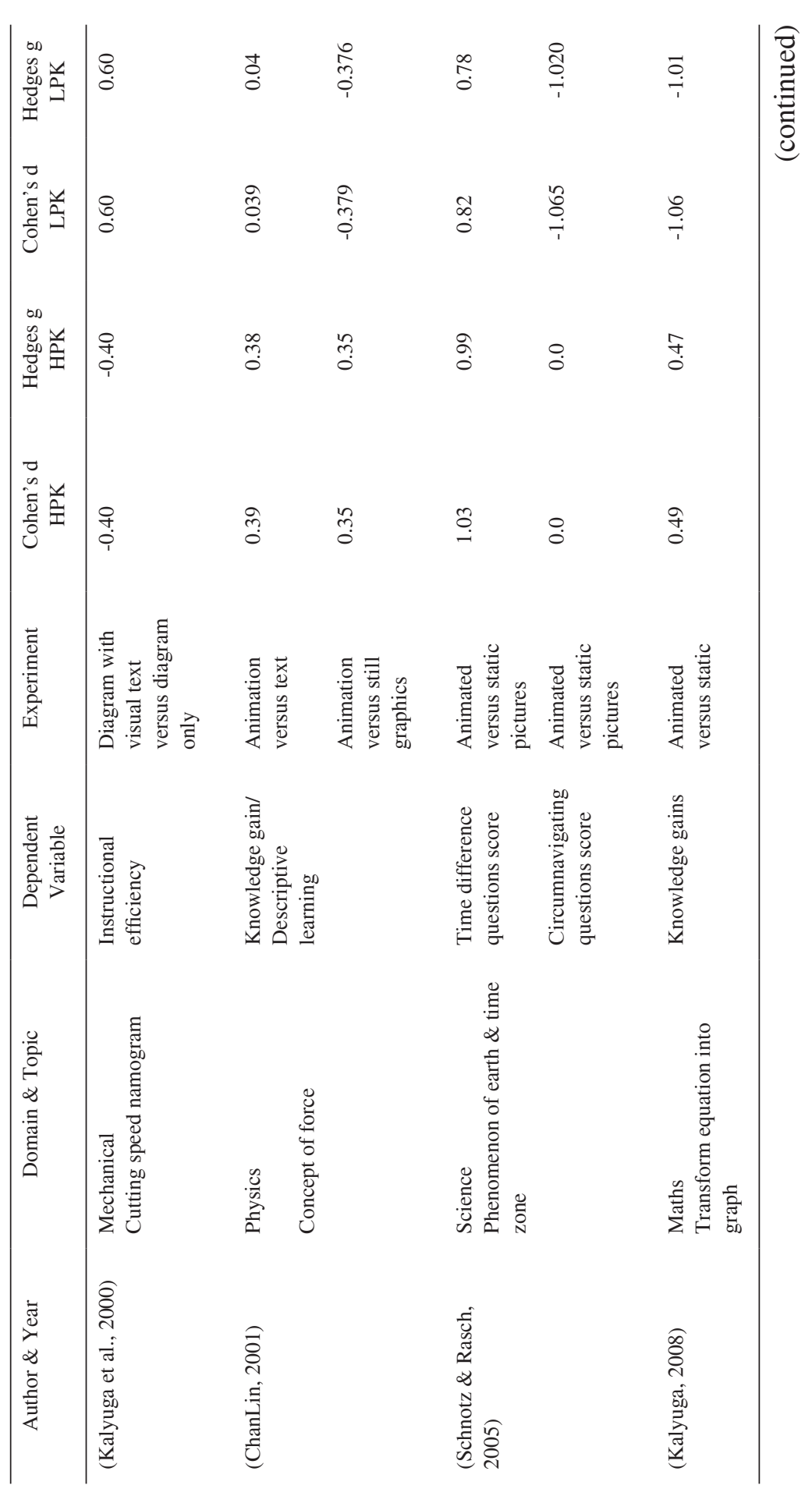




\section{Malaysian Journal of Learning and Instruction: Vol. 16 (No. 1) June 2019: 129-153}

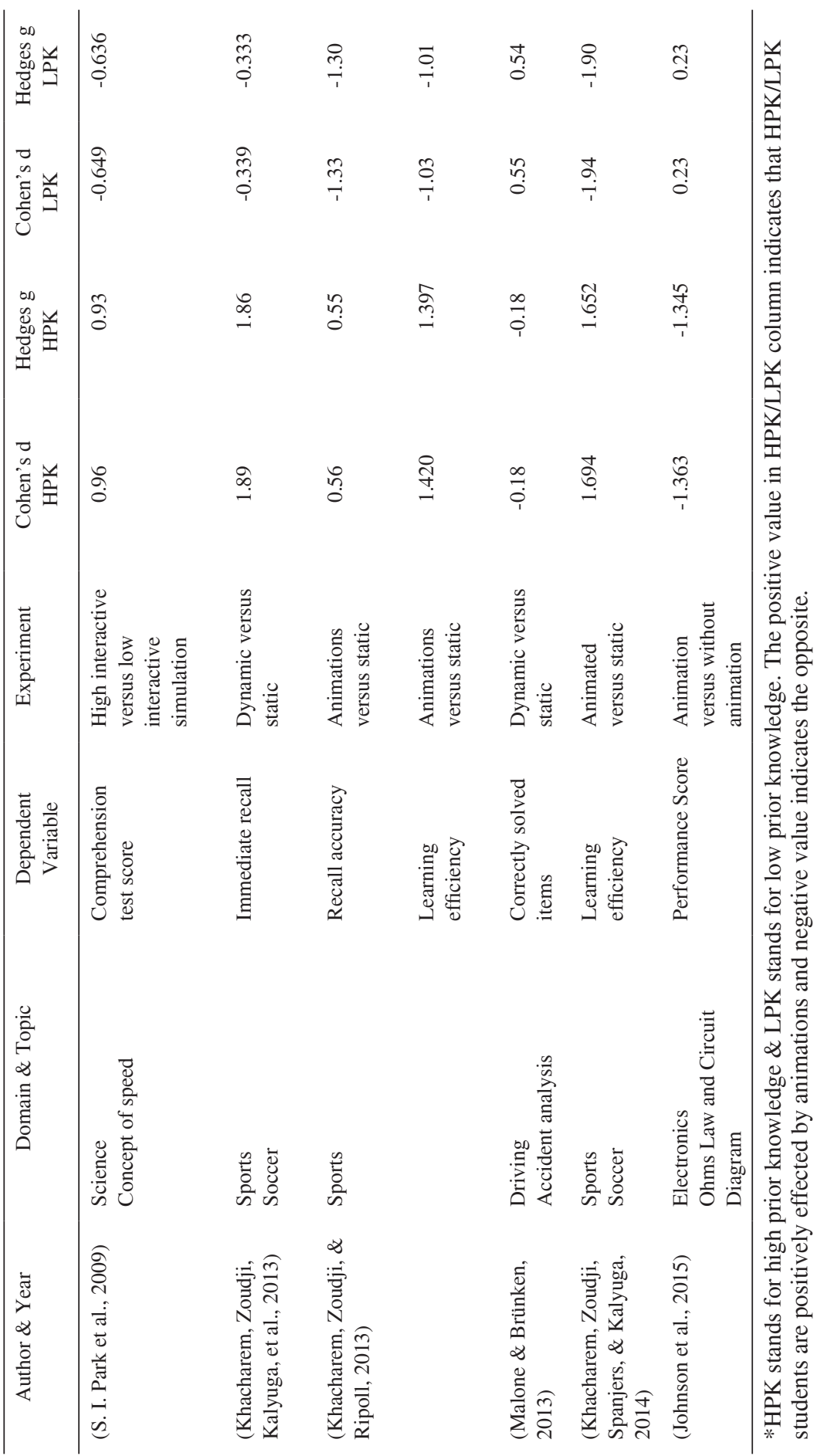


Table 2 demonstrates the effect sizes of an animated environment, non-animated environment and prior knowledge on the learning outcome of HPK and LPK groups. To achieve the purpose, relevant published empirical data of various subject disciplines were collected. The data set includes empirical data of different areas like mechanical, biotechnology, physics, science, sports and electronics. Most of this research is based on the impact of prior knowledge and animation based teaching style on the learning outcomes.

\section{RESULTS}

\section{Result Analysis: Spatial Ability, Teaching Style and Learning Outcome}

Once the data was collected, it was analyzed by calculating the effect sizes and then by calculating the overall mean effect sizes of low spatial ability experiments and high spatial ability experiments. The effect sizes presented a fair estimate of the magnitude and direction of the experiment. By examining the mean effect size, one can easily predict in which condition animation based teaching style is effective. A positive effect size value indicates that the group is positively affected by animations and a negative value indicates the opposite. The graph of the effect sizes of all 20 experiments is shown in Figure 1.

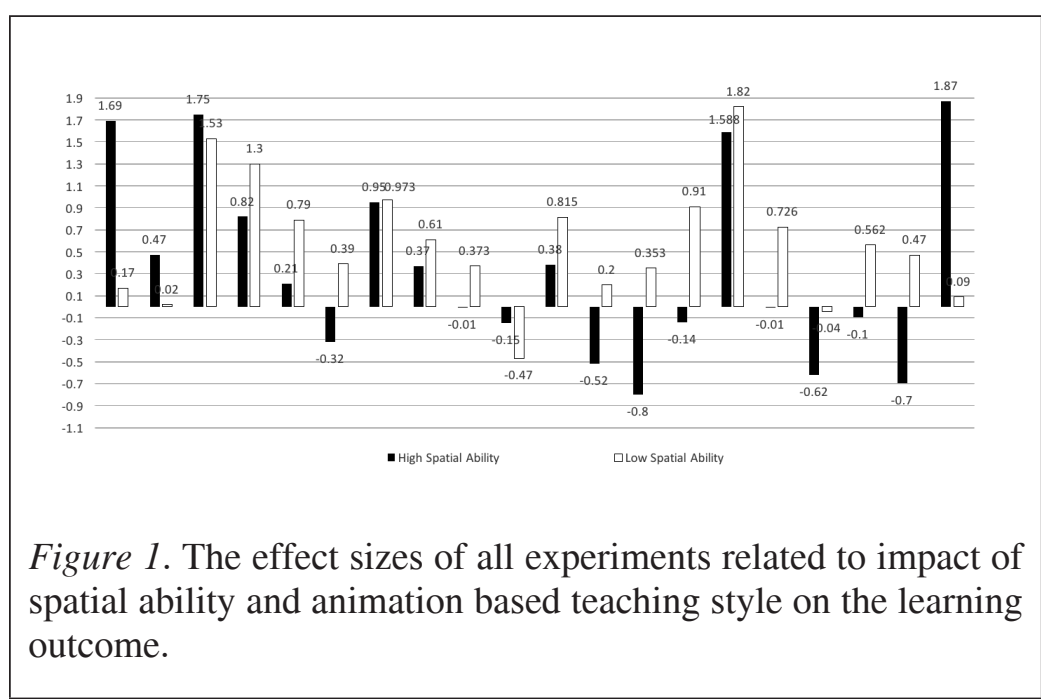


The weighted mean effect size of the HSA and LSA experiments were then separately computed from the previously computed effect sizes of individual experiments. The Shapiro-Wilk normality test was initially performed before computing the mean effect size. The data was found to be normally distributed (See Table 3). Moreover, there were no outliers in the data sets.

Table 3

Normality Test for HSA and LSA Effect Sizes Data Set

\begin{tabular}{lcccccc}
\hline & \multicolumn{2}{c}{ Kolmogorov-Smirnov $^{\mathrm{a}}$} & \multicolumn{3}{c}{ Shapiro-Wilk } \\
\cline { 2 - 3 } \cline { 6 - 7 } & Statistic & $\mathrm{df}$ & Sig. & Statistic & $\mathrm{df}$ & Sig. \\
\hline LSA & .092 & 20 & $.200^{*}$ & .972 & 20 & .804 \\
HSA & .158 & 20 & $.200^{*}$ & .913 & 20 & .072 \\
\hline
\end{tabular}

*Shapiro-Wilk test assumes normality if $\mathrm{p}>.05$

After computation, the weighted mean effect size of HSA groups and LSA groups were 0.34 and 0.58 respectively. The outcomes are shown in Figure 2 on the scale of 0 to 1 . It suggests that both groups were positively affected by animation based teaching style as both effect sizes were positive. Thus, the general assumption that animations are only effective for HSA is not true. Therefore, the null hypothesis for the first objective is rejected. The data concludes that animations are effective for both HSA and LSA students.

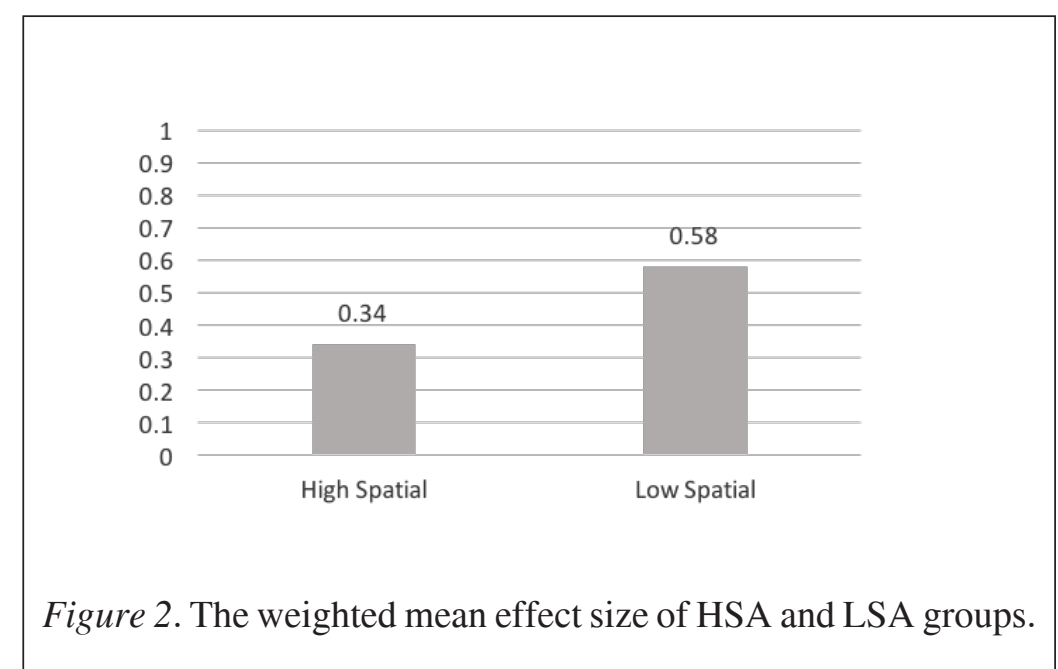


Malaysian Journal of Learning and Instruction: Vol. 16 (No. 1) June 2019: 129-153 145

\section{Result Analysis: Prior Knowledge, Teaching Style and Learning Outcome}

Once the data related to prior knowledge, teaching style, and learning outcome was collected, the data was analyzed by first calculating the effect sizes and then by calculating the overall mean effect sizes of LPK experiments and HPK experiments. Upon investigating the mean effect size, it can determine the condition where animation based teaching style is effective. A positive effect size value indicates that the group is positively affected by animation and a negative value indicates the opposite. The graph of effect sizes of all the 17 experiments is shown in Figure 3.

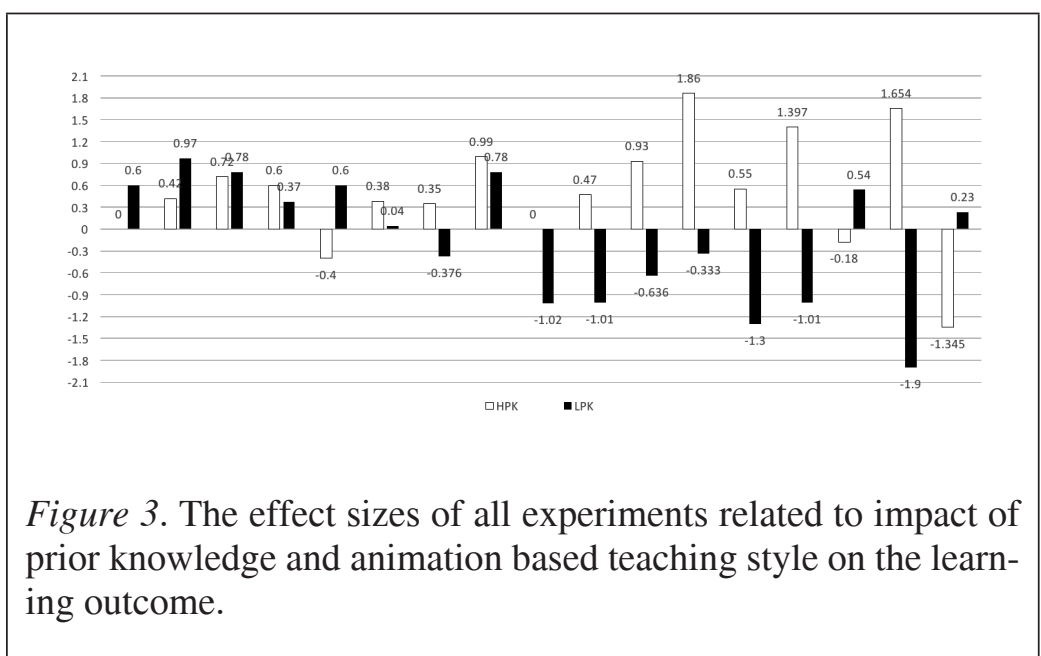

Table 4

Normality Test on HPK and LPK Effect Sizes Data Set

\begin{tabular}{lcccccc}
\hline & \multicolumn{3}{c}{ Kolmogorov-Smirnov $^{\mathrm{a}}$} & \multicolumn{3}{c}{ Shapiro-Wilk } \\
\cline { 2 - 7 } & Statistic & $\mathrm{df}$ & Sig. & Statistic & df & Sig. \\
\hline HPK & .133 & 17 & $.200^{*}$ & .969 & 17 & .807 \\
LPK & .143 & 17 & $.200^{*}$ & .928 & 17 & .201 \\
\hline *Shapiro-Wilk test assumes normality if $\mathrm{p}>.05$ &
\end{tabular}

The Shapiro-Wilk normality test was performed before computing the overall mean effect size and data was found to be normally 
distributed (See Table 4). Moreover, there was no outlier in the data sets.

The overall mean effect size of HPK and LPK groups are shown in Figure 4 on the scale of 0 to 1 on a positive range and 0 to -1 on a negative range. Figure 4 indicates that animation based teaching style is not beneficial for LPK students. The overall mean effect size of HPK students, when taught by animated agents, is 0.49 , whereas the mean effect size of LPK students is -0.16 . Hence, based on the results, the general assumption that animations are only effective for HPK students is true. Thus, we are unable to reject the null hypothesis of the second objective.

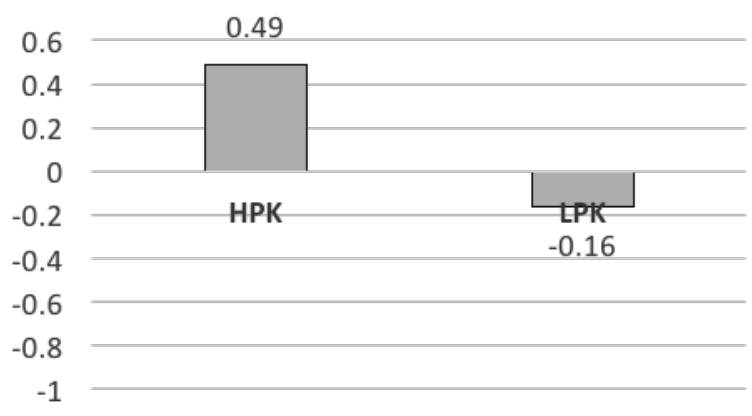

Figure 4. The weighted mean effect size of HPK and LPK groups.

\section{DISCUSSION}

This study investigated the effect of individual differences and teaching style on the learning outcome. The study focused on the two primary individual differences namely learner's spatial ability and prior knowledge and two primary teaching styles namely animated and non-animated. This present research can help educators to decide under which conditions animations would be suitable to enhance learning outcomes.

Earlier, it was a common belief that animations are effective in all conditions. Mixed results of past experimental studies rejected this 
Malaysian Journal of Learning and Instruction: Vol. 16 (No. 1) June 2019: 129-153 147

belief. So, this research was aimed at finding the effect on individual differences and teaching style on the learning-outcomes. This study indicates that prior knowledge of the domain/topic should be considered as the most important factor as teaching through animations to LPK students were ineffective as generally, they were unable to perform well. On the other hand, the interaction of spatial ability and animations is positive for both HSA and LSA groups. Another outcome of this research states that LSA students on the average, performed better than HSA students in the first condition. Thus, in the future, a detailed investigation is required to find the factors which motivate the LSA students to outperform. It is believed that LSA students cannot make independent mental models of the concept. This may be the reason that they outperformed while learning through animations as animated environment presents a ready-made model of concepts and thus helps in reducing cognitive load.

In the future, this belief needs to be proven statistically. This study included empirical data of studies from different domains like mechanical, science, medical, chemistry and other fields of study, but the researchers further recommend that the effect of individual differences and animation based teaching style on learning outcomes should be evaluated according to specific domain in the future.

\section{CONCLUSION}

This study demonstrates that dynamic visualization learning material like animations do not possess a negative impact on either HSA or LSA students. There are individual studies that show negative impact of animations on HSA as well as LSA students but the overall weighted mean effect size presents a positive direction for both the groups (0.34/HSA and $0.58 / \mathrm{LSA})$ when taught through animations. The results also indicate a negative effect of animations for LPK students (-0.16/LPK) while HPK students are positively effected (0.49/HPK) through animation based learning. Thus, statistical evidences were obtained to suggest that prior knowledge is a crucial factor while offering animations and it should only be offered to the HPK students. 
The results of this study also indicate that animations cannot be assumed to be effective for everyone. We recommend that sufficient knowledge regarding concept must first be shared with LPK students before teaching them with animations. In fact, other modes of learning should be used to enhance the prior knowledge of LPK learners and subsequently, animation based teaching methodology should be introduced to them. This is another area of research for the future.

When further research is conducted, there are two main limitations that should be addressed. The first limitation is that it does not find the impact of animation based teaching environment and individual differences (learner's spatial ability and prior knowledge) on the learning outcomes with respect to specific age group. The second limitation is that even though it proves statistically that animation based teaching environment is beneficial for both HSA and LSA learners but it does not find the factors which motivates the LSA learners to outperform.

\section{ACKNOWLEDGEMENT}

This research received no specific grant from any funding agency in the public, commercial, or not-for profit sectors.

\section{REFERENCES}

Abdullah, A. B. M., \& Ligon, J. (2006). The relationship between learning style and quantitative/qualitative information recall performance. Malaysian Journal of Learning \& Instruction, $3,141-158$.

Ainsworth, S., \& VanLabeke, N. (2004). Multiple forms of dynamic representation. Learning and Instruction, 14(3), 241-255.

Azman, N., Mohd Ali, M., Tamuri, A. H., \& Mohd Jelas, Z. (2005). Effective higher educational practices-A survey of student engagement. Malaysian Journal of Learning \& Instruction, $2,95-119$.

Berney, S., \& Bétrancourt, M. (2016). Does animation enhance learning? A meta-analysis. Computers \& Education, 101, $150-167$. 
Berney, S., Bétrancourt, M., Molinari, G., \& Hoyek, N. (2015). How spatial abilities and dynamic visualizations interplay when learning functional anatomy with 3D anatomical models. Anatomical Sciences Education, 8(5), 452-462.

Boucheix, J.-M., \& Schneider, E. (2009). Static and animated presentations in learning dynamic mechanical systems. Learning and Instruction, 19(2), 112-127.

Brünken, R., Steinbacher, S., \& Leutner, D. (2000). R\{ä\}umliches Vorstellungsverm $\{\ddot{ }\}$ gen und Lernen mit Multimedia. Neue Medien in Unterricht, Aus-Und Weiterbildung, 37-46.

Byrne, M. D., Catrambone, R., \& Stasko, J. T. (1999). Evaluating animations as student aids in learning computer algorithms. Computers \& Education, 33(4), 253-278.

Canham, M., \& Hegarty, M. (2010). Effects of knowledge and display design on comprehension of complex graphics. Learning and Instruction, 20(2), 155-166.

Chandler, P. (2004). The crucial role of cognitive processes in the design of dynamic visualizations. Learning and Instruction, 14(3), 353-357.

ChanLin, L. (2001). Formats and prior knowledge on learning in a computer-based lesson. Journal of Computer Assisted Learning, 17(4), 409-419.

Chanlin, L.-J. (1999). Visual treatment for different prior knowledge. International Journal of Instructional Media, 26(2), 213.

Cornoldi, C., \& Vecchi, T. (2004). Visuo-spatial working memory and individual differences. Psychology Press.

Ekstrom, R. B., Dermen, D., \& Harman, H. H. (1976). Manual for kit offactor-referenced cognitive tests (Vol. 102). Educational Testing Service Princeton, NJ.

Fong, S. F. (2013). Effects of segmented animated graphics among students of different spatial ability levels: A cognitive load perspective. TOJET: The Turkish Online Journal of Educational Technology, 12(2).

Garg, A., Norman, G. R., Spero, L., \& Maheshwari, P. (1999). Do virtual computer models hinder anatomy learning? Academic Medicine.

Garg, A. X., Norman, G., \& Sperotable, L. (2001). How medical students learn spatial anatomy. The Lancet, 357(9253), 363364.

Hays, T. A. (1996). Spatial abilities and the effects of computer animation on short-term and long-term comprehension. Journal of Educational Computing Research, 14(2), 139-155. 
Hedges, L. V, \& Olkin, I. (1985). Statistical Methods for Metaanalysis Meta-analysis. Orlando, FL: Academic Press.. Orlando, FL: Academic Press.

Hegarty, M. (2004). Dynamic visualizations and learning: Getting to the difficult questions. Learning and Instruction, 14(3), $343-351$.

Hegarty, M. (2005). Multimedia learning about physical systems. The Cambridge Handbook of Multimedia Learning, 447-465.

Hegarty, M., Canham, M. S., \& Fabrikant, S. I. (2010). Thinking about the weather: How display salience and knowledge affect performance in a graphic inference task. Journal of Experimental Psychology: Learning, Memory, and Cognition, 36(1), 37.

Hegarty, M., \& Kozhevnikov, M. (1999). Types of visual--spatial representations and mathematical problem solving. Journal of Educational Psychology, 91(4), 684.

Hegarty, M., \& Kriz, S. (2008). Effects of knowledge and spatial ability on learning from animation. Learning with Animation: Research Implications for Design, 3-29.

Hegarty, M., Kriz, S., \& Cate, C. (2003). The roles of mental animations and external animations in understanding mechanical systems. Cognition and Instruction, 21(4), 209249.

Hegarty, M., \& Waller, D. (2005). Individual differences in spatial abilities. The Cambridge Handbook of Visuospatial Thinking, 121-169.

Höffler, T. N., \& Leutner, D. (2007). Instructional animation versus static pictures: A meta-analysis. Learning and Instruction, 17(6), 722-738.

Höffler, T. N., Prechtl, H., \& Nerdel, C. (2010). The influence of visual cognitive style when learning from instructional animations and static pictures. Learning and Individual Differences, 20(5), 479-483.

Hui-Yu, Y. (2016). The effects of attention cueing on visualizers' multimedia learning. Journal of Educational Technology \& Society, 19(1), 249.

Huk, T. (2006). Who benefits from learning with 3D models? The case of spatial ability. Journal of Computer Assisted Learning, 22(6), 392-404. 
Isaak, M. I., \& Just, M. A. (1995). Constraints on the processing of rolling motion: The curtate cycloid illusion. Journal of Experimental Psychology: Human Perception and Performance, 21(6), 1391.

Johnson, A. M., Ozogul, G., \& Reisslein, M. (2015). Supporting multimedia learning with visual signalling and animated pedagogical agent: Moderating effects of prior knowledge. Journal of Computer Assisted Learning, 31(2), 97-115.

Kalyuga, S. (2007). Expertise reversal effect and its implications for learner-tailored instruction. Educational Psychology Review, 19(4), 509-539.

Kalyuga, S. (2008). Relative effectiveness of animated and static diagrams: An effect of learner prior knowledge. Computers in Human Behavior, 24(3), 852-861.

Kalyuga, S., Chandler, P., \& Sweller, J. (1998). Levels of expertise and instructional design. Human Factors, 40(1), 1-17.

Kalyuga, S., Chandler, P., \& Sweller, J. (2000). Incorporating learner experience into the design of multimedia instruction. Journal of Educational Psychology, 92(1), 126.

Kalyuga, S., Chandler, P., \& Sweller, J. (2001). Learner experience and efficiency of instructional guidance. Educational Psychology, 21(1), 5-23.

Kalyuga, S., \& Sweller, J. (2005). Rapid dynamic assessment of expertise to improve the efficiency of adaptive e-learning. Educational Technology Research and Development, 53(3), 83-93.

Khacharem, A., Zoudji, B., Kalyuga, S., \& Ripoll, H. (2013). Developing tactical skills through the use of static and dynamic soccer visualizations: An expert--nonexpert differences investigation. Journal of Applied Sport Psychology, 25(3), 326-340.

Khacharem, A., Zoudji, B., \& Ripoll, H. (2013). Effect of presentation format and expertise on attacking-drill memorization in soccer. Journal of Applied Sport Psychology, 25(2), 234-248.

Khacharem, A., Zoudji, B., Spanjers, I. A. E., \& Kalyuga, S. (2014). Improving learning from animated soccer scenes: Evidence for the expertise reversal effect. Computers in Human Behavior, 35, 339-349.

Khooshabeh, P., \& Hegarty, M. (2010). Inferring cross-sections: When internal visualizations are more important than properties of external visualizations. Human--Computer Interaction, 25(2), 119-147. 
Kriz, S., \& Hegarty, M. (2007). Top-down and bottom-up influences on learning from animations. International Journal of HumanComputer Studies, 65(11), 911-930.

Large, A., Beheshti, J., Breuleux, A., \& Renaud, A. (1996). Effect of animation in enhancing descriptive and procedural texts in a multimedia learning environment. Journal of the American Society for Information Science, 47(6), 437-448.

Lee, D. Y., \& Shin, D.-H. (2011). Effects of spatial ability and richness of motion cue on learning in mechanically complex domain. Computers in Human Behavior, 27(5), 1665-1674.

Lee, E. A.-L., \& Wong, K. W. (2014). Learning with desktop virtual reality: Low spatial ability learners are more positively affected. Computers \& Education, 79, 49-58.

Lowe, R. K. (1999). Extracting information from an animation during complex visual learning. European Journal of Psychology of Education, 14(2), 225-244.

Malakolunthu, S., \& Joshua, A. (2012). Learning Approaches of Undergraduate Computer Technology Students: Strategies for Improvement. Malaysian Journal of Learning and Instruction, 9, 1-14.

Malone, S., \& Brünken, R. (2013). Assessment of driving expertise using multiple choice questions including static vs. animated presentation of driving scenarios. Accident Analysis \& Prevention, 51, 112-119.

Mayer, R. E., \& Anderson, R. B. (1992). The instructive animation: Helping students build connections between words and pictures in multimedia learning. Journal of Educational Psychology, 84(4), 444.

Mayer, R. E., DeLeeuw, K. E., \& Ayres, P. (2007). Creating retroactive and proactive interference in multimedia learning. Applied Cognitive Psychology, 21(6), 795-809.

Mayer, R. E., \& Gallini, J. K. (1990). When is an illustration worth ten thousand words? Journal of Educational Psychology, 82(4), 715.

Mayer, R. E., \& Sims, V. K. (1994). For whom is a picture worth a thousand words? Extensions of a dual-coding theory of multimedia learning. Journal of Educational Psychology, 86(3), 389.

Moreno, R., \& Mayer, R. (2007). Interactive multimodal learning environments. Educational Psychology Review, 19(3), 309326. 
Narayanan, N. H., \& Hegarty, M. (2002). Multimedia design for communication of dynamic information. International Journal of Human-Computer Studies, 57(4), 279-315.

Nguyen, N., Nelson, A. J., \& Wilson, T. D. (2012). Computer visualizations: Factors that influence spatial anatomy comprehension. Anatomical Sciences Education, 5(2), 98108.

Ollerenshaw, A., Aidman, E., \& Kidd, G. (1997). Is an illustration always worth ten thousand words? Effects of prior knowledge, learning style and multimedia illustrations on text comprehension. International Journal of Instructional Media, 24(3), 227.

Paas, F., Renkl, A., \& Sweller, J. (2003). Cognitive load theory and instructional design: Recent developments. Educational Psychologist, 38(1), 1-4.

Park, O., \& Gittelman, S. S. (1992). Selective use of animation and feedback in computer-based instruction. Educational Technology Research and Development, 40(4), 27-38.

Park, S. I., Lee, G., \& Kim, M. (2009). Do students benefit equally from interactive computer simulations regardless of prior knowledge levels? Computers \& Education, 52(3), 649-655.

Peters, M., Laeng, B., Latham, K., Jackson, M., Zaiyouna, R., \& Richardson, C. (1995). A redrawn Vandenberg and Kuse mental rotations test-different versions and factors that affect performance. Brain and Cognition, 28(1), 39-58.

Plass, J. L., Chun, D. M., Mayer, R. E., \& Leutner, D. (2003). Cognitive load in reading a foreign language text with multimedia aids and the influence of verbal and spatial abilities. Computers in Human Behavior, 19(2), 221-243.

Rieber, L. P. (1990). Using computer animated graphics in science instruction with children. Journal of Educational Psychology, 82(1), 135.

Schnotz, W., \& Rasch, T. (2005). Enabling, facilitating, and inhibiting effects of animations in multimedia learning: Why reduction of cognitive load can have negative results on learning. Educational Technology Research and Development, 53(3), 47.

Sims, V. K., \& Hegarty, M. (1997). Mental animation in the visuospatial sketchpad: Evidence from dual-task studies. Memory \& Cognition, 25(3), 321-332. 